\title{
Josiane Boulad-Ayoub, L'abbé Grégoire apologète de la République
}

Paola Salerni

\section{OpenEdition}

\section{Edizione digitale}

URL: http://journals.openedition.org/studifrancesi/27658

DOI: 10.4000/studifrancesi.27658

ISSN: 2421-5856

\section{Editore}

Rosenberg \& Sellier

\section{Edizione cartacea}

Data di pubblicazione: 31 décembre 2006

Paginazione: 610

ISSN: 0039-2944

\section{Notizia bibliografica digitale}

Paola Salerni, « Josiane Boulad-Ayoub, L'abbé Grégoire apologète de la République », Studi Francesi

[Online], 150 (L | III) | 2006, online dal 30 novembre 2015, consultato il 08 novembre 2020. URL : http:// journals.openedition.org/studifrancesi/27658; DOI : https://doi.org/10.4000/studifrancesi.27658

Questo documento è stato generato automaticamente il 8 novembre 2020.

\section{(c) $(7)$}

Studi Francesi è distribuita con Licenza Creative Commons Attribuzione - Non commerciale - Non opere derivate 4.0 Internazionale. 


\title{
Josiane Boulad-Ayoub, L'abbé Grégoire apologète de la République
}

\author{
Paola Salerni
}

\section{NOTIZIA}

JOSIANE BOULAD-AYOUB, L'abbé Grégoire apologète de la République, Paris, Champion, 2005, pp. 254.

1 Josiane Boulad-Ayoub ripercorre la complessa personalità dell'abbé Grégoire, coscienza morale e politica della Rivoluzione francese, ricomponendo in una forma agile ma densamente strutturata da riferimenti storici e riletture critiche, il lavoro dell'uomo di Chiesa che conciliava, senza contrasti, la sincera fede cristiana con l'attività di deputato, di senatore e di repubblicano convinto.

2 Dopo il ritratto del religioso, attraverso il quale la studiosa mette in evidenza i tratti salienti del carattere, è ricostruita la situazione storica e politica della Francia, cornice e terreno esistenziale del vescovo-deputato. Si analizzano successivamente i capisaldi dell'apologetica cattolica della seconda parte del XVIII secolo, confrontando le argomentazioni degli ecclesiastici in materia di conoscenza e libertà di coscienza con le «innovations» dei philosophes, colpevoli di non riconoscere le verità della religione rivelata e denunciati dallo stesso Grégoire tanto nell'Histoire de l'Eglise quanto nelle Ruines de Port-Royal-des-Champs. Il saggio, arricchito nella seconda parte dalla pubblicazione della Motion en faveur des Juifs, dal Mémoire en faveur des gens de couleur e dal Discours sur la liberté des cultes, accompagnati da una breve ma completa contestualizzazione storica, ricostruisce le battaglie più accanite condotte dall'abbé Grégoire in difesa degli oppressi e delle minoranze di ogni genere, distinguendo la dimensione religiosa incarnata del militante cristiano dall'ideologia dei Lumi sui principi di tolleranza e di libertà, ricondotte alle antiche verità del cristianesimo che riconoscono all'uomo il potere della ragione, ma gli assegnano la dignità e i limiti di “creatura di Dio". In questo modo l'abbé Grégoire affermava i principi anticipatori di 
una universalità di "droit", ma anche di "devoir", un'emancipazione dell'individuo dal dispotismo sia religioso che monarchico dai tratti estremamente moderni, per affermare l'emancipazione degli ebrei, l'abolizione della schiavitù, la denuncia dell'Inquisizione, la rivendicazione della libertà di culto fino alle innovazioni istituzionali più importanti come la costituzione del "Conservatoire des arts er métiers", il "Bureau des longitudes" e l' "Institut national", per finire con l'opposizione a Napoleone nel Projet de déchéance de Napoléon e la critica alla Constitution française del 1814.

Scavando fra i motivi ideologici nodali, l'autrice mette in luce i collegamenti fra la lotta personale dell'abbé Grégoire e la Rivoluzione, da lui interpretata quale segno provvidenziale, simbolo teologico scaturito da quelle Lumières che lo avrebbero aiutato a "rigenerare" la Chiesa nazionale. Lo scopo era il ritorno a una Chiesa primitiva priva di dispotismo gerarchico, ad una forma di conciliarismo quale espressione di sovranità collettiva. Sono così individuati quegli aspetti che fanno dello scrittore «le dernier des apologètes chrétiens», capace di conciliare i classici, come Montesquieu, Rousseau e Mably, con gli Idéologues di Auteuil e di applicare le loro tesi a tutti i "citoyens", senza distinzione di razza, religione e colore di pelle. Il tentativo mirava ad accelerare il progresso dell' "esprit public», soprattutto attraverso la diffusione della stessa lingua nazionale: la sostituzione dei dialetti regionali e del latino con la lingua della Déclaration des droits e degli uomini di cultura e di scienza che hanno fatto la gloria della Francia, sostenuta da un nuovo sistema di istruzione pubblica, avrebbe favorito l'unificazione del Paese e rinforzato lo spirito d'eguaglianza, senza nessuna distinzione. L'abbé Grégoire combatteva anche per un sistema politico basato sulla tolleranza universale, espressione di una volontà di régénération, parola cristiana confluita nella sfera civile. Ancora più significativa dunque è la segnalazione della nuova definizione di tolérantisme affermata dal Dictionnaire de l'Académie del 1798, ad opera del Comité d'instruction publique: la nuova autorità istituzionale in materia linguistica distingueva fra «tolérance civile et religieuse» e denunciava il valore ideologico di questo "principe et [...] droit» che disgiunge la Chiesa dallo Stato e la teologia dal diritto.

4 L'altro punto di forza su cui Josiane Boulad-Ayoub fonda la sua interessante indagine è lo spirito di solidarietà che l'abbé Grégoire, patriota rivoluzionario e figlio dell'Illuminismo, persegue per costruire una società repubblicana cristiana degli intellettuali di tutti i paesi, liberi perché virtuosi e lontani dai pregiudizi dell'ancien régime. 